\title{
Basal conditions for Pine Island and Thwaites Glaciers, West Antarctica, determined using satellite and airborne data
}

\author{
Ian JOUGHIN, ${ }^{1}$ Slawek TULACZYK, ${ }^{2}$ Jonathan L. BAMBER, ${ }^{3}$ Don BLANKENSHIP, \\ John W. HOLT, ${ }^{4}$ Ted SCAMBOS, ${ }^{5}$ David G. VAUGHAN ${ }^{6}$ \\ ${ }^{1}$ Polar Science Center, Applied Physics Laboratory, University of Washington, 1013 NE 40th Street, Seattle, \\ Washington 98105-6698, USA \\ E-mail: ian@apl.washington.edu \\ ${ }^{2}$ Department of Earth Sciences, A208 Earth and Marine Sciences Bldg., University of California Santa Cruz, Santa Cruz, \\ California 95064, USA \\ ${ }^{3}$ Centre for Polar Observations and Modelling, School of Geographical Sciences, University of Bristol, University Road, \\ Bristol BS8 1SS, UK \\ ${ }^{4}$ Jackson School of Geosciences, University of Texas at Austin, 10100 Burnet Road, Bldg. 196, Austin, Texas 78758, USA \\ ${ }^{5}$ National Snow and Ice Data Center, CIRES, University of Colorado, Boulder, Colorado 80309-0449, USA \\ ${ }^{6}$ British Antarctic Survey, Natural Environment Research Council, Madingley Road, Cambridge CB3 OET, UK
}

\begin{abstract}
We use models constrained by remotely sensed data from Pine Island and Thwaites Glaciers, West Antarctica, to infer basal properties that are difficult to observe directly. The results indicate strong basal melting in areas upstream of the grounding lines of both glaciers, where the ice flow is fast and the basal shear stress is large. Farther inland, we find that both glaciers have 'mixed' bed conditions, with extensive areas of both bedrock and weak till. In particular, there are weak areas along much of Pine Island Glacier's main trunk that could prove unstable if it retreats past the band of strong bed just above its current grounding line. In agreement with earlier studies, our forward ice-stream model shows a strong sensitivity to small perturbations in the grounding line position. These results also reveal a large sensitivity to the assumed bed (sliding or deforming) model, with non-linear sliding laws producing substantially greater dynamic response than earlier simulations that assume a linear-viscous till rheology. Finally, comparison indicates that our results using a plastic bed are compatible with the limited observational constraints and theoretical work that suggests an upper bound exists on maximum basal shear stress.
\end{abstract}

\section{INTRODUCTION}

While there is little mass loss for much of Antarctica, the glaciers along the Amundsen Coast are thinning rapidly (Shepherd and others, 2002; Rignot and others, 2008). Increases in speed on some of these glaciers have caused the Amundsen Sea region's contribution to sea level to increase from $0.11 \mathrm{~mm} \mathrm{a}^{-1}$ in 1996 to $0.25 \mathrm{~mm} \mathrm{a}^{-1}$ in 2006 (Rignot and others, 2008). These thinning rates are expected to increase further if these glaciers retreat into their deep basins (Thomas and others, 2004a,b).

Some of the most dramatic changes along the Amundsen Coast have occurred on Pine Island Glacier where the speed near the grounding line increased by $25 \%$ between 1974 and 2003 (Rignot and others, 2002; Joughin and others, 2003b; Rabus and Lang, 2003) with additional increases through 2008 (Rignot and others, 2008). Satellite altimetry from Pine Island Glacier shows that thinning $\left(>1 \mathrm{~m} \mathrm{a}^{-1}\right)$ on the floating ice and regions just above the grounding line extends well inland $(200 \mathrm{~km})$ but at reduced magnitude $\left(\sim 10 \mathrm{~cm} \mathrm{a}^{-1}\right)$ (Shepherd and others, 2001). Although inland thinning rates are an order of magnitude smaller than coastal rates, they span a far greater area so that much of the total volume loss is from the ice sheet's interior (Joughin and others, 2003b). While thinning rates on Thwaites Glacier are similarly large, changes in speed on this glacier are more modest (Rignot and others, 2002), suggesting an ongoing response to a speed-up that may have occurred prior to satellite observations (Rignot and others, 2008).
There is growing evidence that changes on the ice sheet are caused by oceanographic change. The inflow of warmer Circumpolar Deep Water onto the continental shelf has increased melting beneath floating ice shelves (Jacobs and others, 1996; Rignot and Jacobs, 2002) and altered ice-sheet mass balance, particularly along the Amundsen Coast, where glaciers discharge into small fringing ice shelves (Payne and others, 2004). Although the melting of floating ice shelves does not directly influence sea level, changes in the geometry of the coupled ice-shelf/ice-sheet system can propagate inland on timescales of decades to produce strong thinning $\left(>10 \mathrm{~cm} \mathrm{a}^{-1}\right)$ at distances of $100 \mathrm{~km}$ or more inland from the grounding line (Shepherd and others, 2001; Schmeltz and others, 2002; Payne and others, 2004; Dupont and Alley, 2005).

Although changes near the grounding line can affect glacier speed and force balance well inland, much of this influence is determined by the properties at the base of the grounded ice sheet. While detailed surface observations are becoming routine, conditions at the glacier bed are far more difficult to observe, although some success has been achieved in using seismic reflection techniques to measure subglacial conditions (e.g. Vaughan and others, 2003). Here we use airborne and satellite remote-sensing data to constrain models to infer the basal conditions (e.g. melt rate and shear stress) that influence the evolution of these rapidly changing glaciers. To examine the dynamic sensitivity to different bed conditions (e.g. power-law sliding and plastic), we performed several experiments where we 


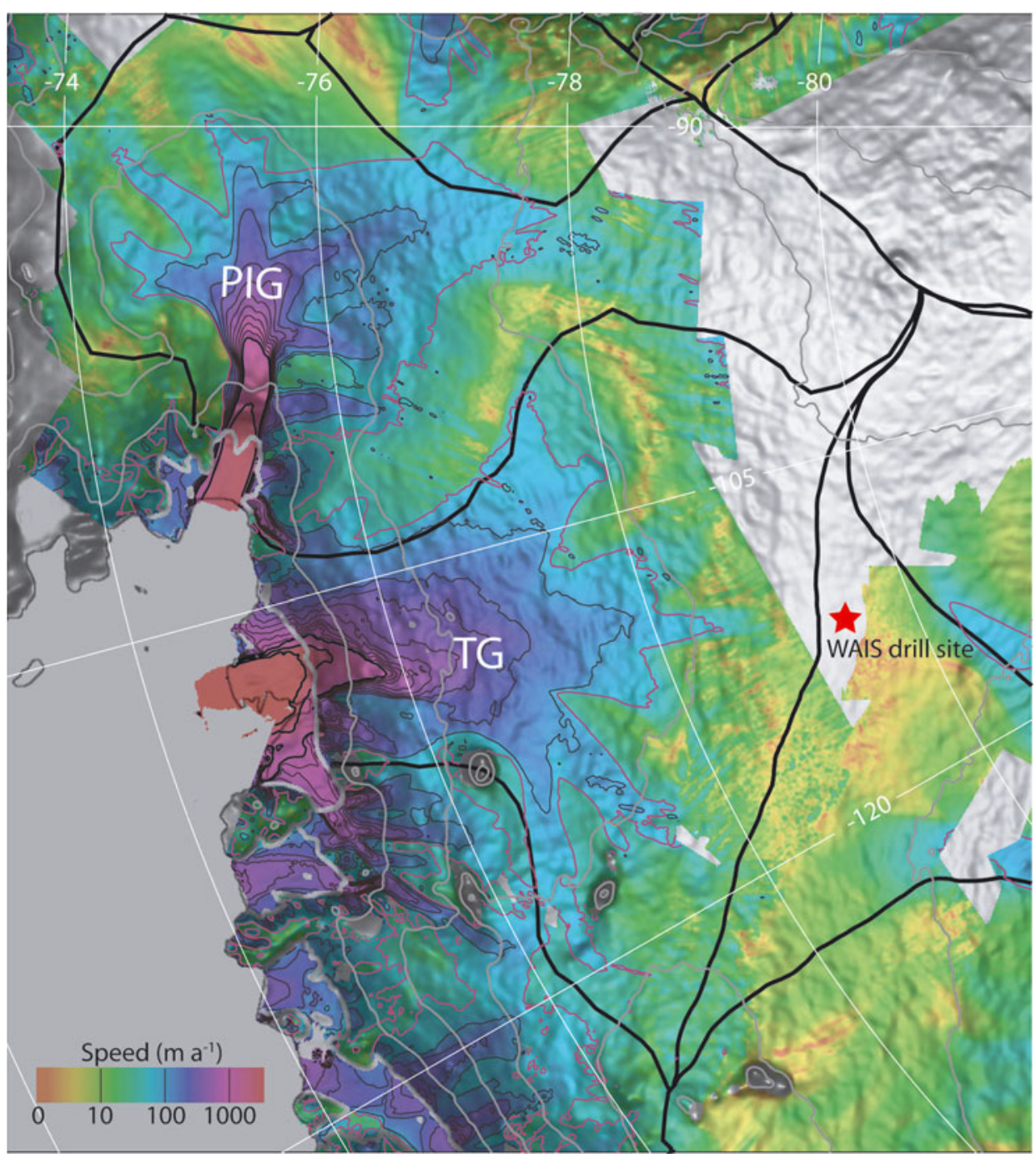

Fig. 1. Flow speed (color) over the artificially shaded surface (grayscale) of a DEM produced from a combination of laser and radar altimetry (see text) for Pine Island (PIG) and Thwaites (TG) Glaciers. Speed is also shown with a $50 \mathrm{~m} \mathrm{a}^{-1}$ contour (purple), $100 \mathrm{~m} \mathrm{a}^{-1}$ contours up to $900 \mathrm{~m} \mathrm{a}^{-1}$ (thin black), and $1000 \mathrm{~m} \mathrm{a}^{-1}$ contours (thick black). Elevations are shown with $500 \mathrm{~m}$ contours (gray). Heavy black curves show the approximate locations of drainage divides.

perturbed the basal shear stress of the forward ice-stream model to simulate grounding-line retreat. While a prognostic model is beyond the scope of this paper, the final result of our efforts is a diagnostic model tuned to match present-day conditions that provides a set of initial conditions that can be used in subsequent predictive modelling studies.

\section{DATA}

Further below we describe results derived using ice-sheet models that are constrained in some form by recently collected datasets, including velocity, elevation and icethickness data. Before describing the models, we briefly describe these datasets.

\subsection{Velocity data}

We produced a map of ice-flow velocity (Fig. 1) for Pine Island and Thwaites Glaciers using the same interferometric synthetic aperture radar (InSAR) and speckle-tracking methods used in earlier studies (e.g. Joughin, 2002). Unlike lower-accumulation areas in West Antarctica where RADARSAT works well (e.g. Joughin and others, 2002), this instrument's 24 day repeat cycle yields poor coherence for velocity mapping in the high-accumulation areas along the Amundsen Coast. As a consequence, we created our map using data acquired by the European Remote-sensing Satellites (ERS-1 and -2), which provide image pairs separated by 1 and 3 days. Because Pine Island Glacier sped up between 1994 and 1996 (Rignot and others, 2002), we used only the 1996 data in the areas where large changes occurred. Hence, our map represents the 1996 speed of the Amundsen Coast glaciers.

In areas where there were crossing orbits available and where we could successfully unwrap the phase, the velocity estimates are largely determined by the phase data with formal errors of about $3-5 \mathrm{~m} \mathrm{a}^{-1}$. In areas without crossing orbits or phase data, speckle tracking with short temporal baselines yields larger uncertainty $\left(5-50 \mathrm{~m} \mathrm{a}^{-1}\right)$. Tidal motion leads to large errors on the floating ice $\left(\sim 100 \mathrm{~m} \mathrm{a}^{-1}\right)$, but, at least on Pine Island Glacier (Joughin and others, 2003b), it is unlikely to be a significant source of uncertainty even when the observation interval is short (J. Scott and others, unpublished information). In addition to these errors, the process for removing vertical 


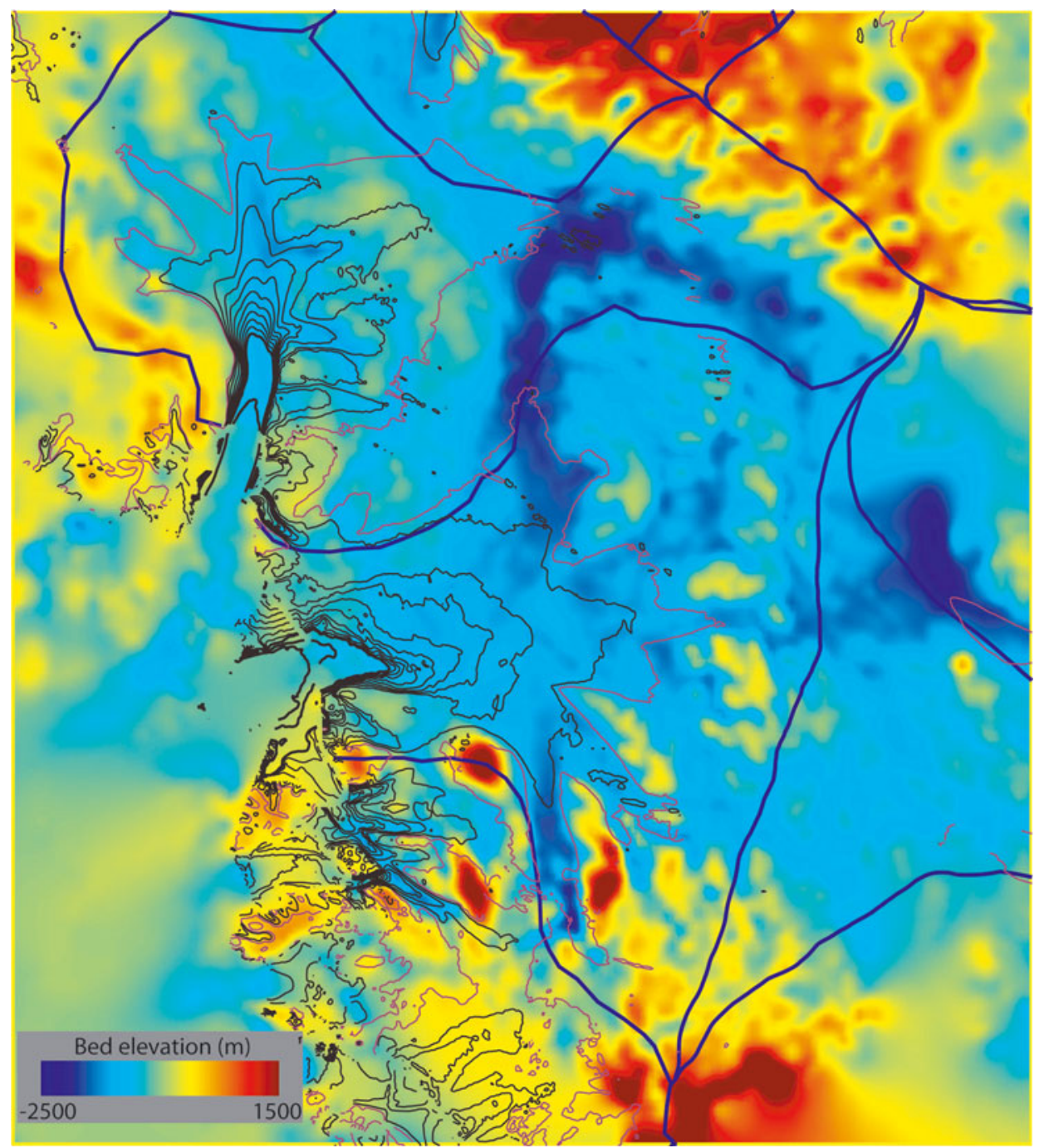

Fig. 2. Bed elevation for Pine Island and Thwaites Glaciers (Vaughan and others, 2006; Holt and others, 2007). Glacier extents are indicated by the contours of glacier speed: $50 \mathrm{~m} \mathrm{a}^{-1}$ contour (purple), $100 \mathrm{~m} \mathrm{a}^{-1}$ contours up to $900 \mathrm{~m} \mathrm{a}^{-1}$ (thin black), and $1000 \mathrm{~m} \mathrm{a}^{-1}$ contours (thick black).

displacements can yield slope-dependent errors of up to $\sim 3 \%$ (Joughin and others, 1998).

\subsection{Elevation data}

The modelling described in the following sections requires accurate estimates of surface elevation (Joughin and others, 2004a). In this study, we use a digital elevation model (DEM) produced using a combination of data from the ERS-1 and -2 radar and Ice, Cloud and land Elevation Satellite (ICESat) laser altimeters (Bamber and others, 2008; Griggs and Bamber, 2008), which is displayed as a shaded relief map in Figure 1.

\subsection{Bed elevation data}

During the 2004/05 austral summer, the British Antarctic Survey and the University of Texas conducted a joint airborne survey of the Pine Island and Thwaites Glacier catchments (Vaughan and others, 2006; Holt and others, 2007). Figure 2 shows the bed elevation map from this survey along with the flow-speed contours from the map shown in Figure 1, illustrating the close correspondence of the fast-flow features with the deep subglacial troughs (Vaughan and others, 2006; Holt and others, 2007).

\section{MODELS}

We used several modelling approaches to examine basal conditions beneath Pine Island and Thwaites Glaciers, which involve the two basic models described in this section. The first is a thermal model, which we used to determine englacial temperatures. The second is a coupled diagnostic ice-stream/ice-shelf model from which we derived results using both forward and inverse approaches. The section ends with a review of the inverse methods that we applied to the forward ice-stream/ice-shelf model to infer basal and rheological parameters.

\subsection{Temperature and melt rates}

We solved for the temperature within an ice column lying atop a homogeneous bedrock slab with depth equal to one ice thickness using methods described by Joughin and others (2004b). In doing so, we neglect horizontal diffusion so that temperature within the ice is determined by the following simplified statement of thermal energy conservation:

$$
\frac{\partial T}{\partial t}+u \frac{\partial T}{\partial x}+v \frac{\partial T}{\partial y}+w \frac{\partial T}{\partial z}=\frac{k_{\mathrm{i}}}{\rho_{\mathrm{i}} c_{\mathrm{i}}} \frac{\partial^{2} T}{\partial z^{2}}+\frac{W}{\rho_{\mathrm{i}} c_{\mathrm{i}}},
$$

where $u, v$ and $w$ are respectively the $x, y$ and $z$ velocity 
components, $c$ is the thermal heat capacity, $k$ is the thermal conductivity, $\rho$ is the density, and $W$ is the strain heating within the ice column due to vertical shear. In this equation the subscript $i$ is used to indicate ice-related parameters, and in the following equation the subscript $r$ is used to indicate bedrock-related parameters. In the underlying bedrock we solve

$$
\frac{\partial T}{\partial t}=\frac{k_{\mathrm{r}}}{\rho_{\mathrm{r}} C_{\mathrm{r}}} \frac{\partial^{2} T}{\partial z^{2}}
$$

which includes only vertical thermal diffusion. Following MacAyeal (1997), we solve Equations (1) and (2) numerically after recasting them in contour-following vertical coordinates. Using initial conditions described in the following paragraphs, we integrate this model forward in time over several thousand years with a fixed geometry (see section 4) to obtain estimates of present-day englacial temperature, which we also use to compute basal melt rates (Joughin and others, 2004b).

In solving Equation (1), we used the InSAR measurements for the horizontal velocity components (Fig. 1). Using this velocity field, we classify each node in the model domain as either fast-moving 'ice-stream' flow or slow-moving 'icesheet' flow, with the boundary separating these node types roughly conforming to the $50 \mathrm{~m} \mathrm{a}^{-1}$ flow-speed contour. For the fast-moving nodes, we assume there is substantial sliding or bed deformation so that a constant flow velocity can be assumed throughout the ice column. At ice-sheet nodes where the velocity is depth-dependent, we assume no sliding and compute the normalized variation of velocity with depth for internal deformation (Paterson, 1994, p. 251). This function is then multiplied by the measured surface velocity to estimate the depth-dependent velocities. We compute a simple linear change in vertical velocity with depth for all nodes, with a basal value of zero and a downward surface value equal to the ice-equivalent accumulation rate, which is based on the average of two gridded accumulation maps (Vaughan and others, 1999; Giovinetto and Zwally, 2000).

Since we use the derived basal temperature gradients to estimate basal melt (see below) and, thus, did not have an a priori basal melt estimate, we neglected the downward advection of ice due to basal melt in our temperature calculations. In regions with a frozen bed, this makes no difference. In the majority of our study area where the melt rates are $<25 \mathrm{~mm} \mathrm{a}^{-1}$, this will bias the magnitudes of our temperature gradients low by $\sim 15 \%$ or less, which is comparable to the effect of errors in the accumulation rate data used in the model. In the fastest-moving areas where the melt rates approach the accumulation rates in magnitude, caution should be exercised in interpreting the temperature gradients. Because nearly all of the heat used to melt ice in these regions is generated by friction from sliding over the bed, the overall effect on our melt rate results is negligible.

We used the same initialization scheme that we employed for our Siple Coast study (Joughin and others, 2004b), which uses an analytical solution for $T$ that accounts for vertical advection and diffusion only (Zotikov, 1986). Throughout the simulation, the temperature at the ice-bedrock interface is maintained at the pressure-melting point, $T_{\mathrm{pmp}}$, for the fast-moving 'ice-stream' nodes (i.e. we assume an infinite reservoir of basal water so that the bed never freezes). For the slow-moving 'ice-sheet nodes', we assume no flow of meltwater from adjacent nodes and no local meltwater storage so that a node freezes to the bed at any time-step when the basal temperature gradient allows upward conduction of heat that can be balanced by the geothermal heat flux. A node that is frozen to the bed switches to a non-frozen state at any time-step where it reaches $T_{\text {pmp }}$.

As part of the initialization process, the model must determine which nodes are melting and which are freezing. We assume that a wet bed enables the fast motion of the ice streams and their tributaries, so these nodes are always assumed to be at $T_{\text {pmp }}$. For the ice-sheet nodes, we use the analytical solution for a frozen bed to determine the bed temperature. If the temperature is below the pressure-melting point, the node is flagged as initially frozen. If the temperature is at or above $T_{\mathrm{pmp}}$ the node initially is considered melted and we initialize temperature by switching to the analytical solution for a thawed bed (Zotikov, 1986).

The temperature boundary condition at the ice-sheet surface is the mean annual surface temperature (Comiso, 1994, 2000). At the bottom of the bedrock layer, the boundary condition is $\partial T / \partial z=-G / k_{\mathrm{r}}$, where $G$ is the geothermal flux and $k_{\mathrm{r}}$ is the conductivity estimated for bedrock below the zone of any weathered or altered layers. These upper and lower boundary conditions are used when the bed is frozen, to jointly solve Equations (1) and (2). If there is melting at the bed, Equations (1) and (2) are solved individually, with the additional boundary condition imposed at the ice-bedrock interface that temperature equals the pressure-melting point, $T_{\text {pmp }}$.

We estimate the basal melt rate, $m_{\mathrm{r}}$ using

$$
m_{\mathrm{r}}=\frac{G+\tau_{\mathrm{b}} U_{\mathrm{b}}-k_{\mathrm{i}} \Theta_{\mathrm{b}}}{L_{\mathrm{i}} \rho_{\mathrm{i}}},
$$

where $\tau_{\mathrm{b}}$ is the magnitude of the basal shear stress, $U_{\mathrm{b}}$ is basal speed, $k_{\mathrm{i}}$ is the thermal conductivity of ice, $\Theta_{\mathrm{b}}$ is the basal temperature gradient, $L_{\mathrm{i}}$ is the latent heat of fusion and $\rho_{\mathrm{i}}$ is the density of ice (Paterson, 1994). We calculate $\Theta_{\mathrm{b}}$ directly from the just described temperature model and use a spatially homogeneous value of $G=70 \mathrm{~mW} \mathrm{~m}^{-2}$ in all our estimates, which corresponds to the geothermal heat flux determined from a borehole at Siple Dome (Engelhardt, 2004). Earlier results estimated $80 \mathrm{~mW} \mathrm{~m}^{-2}$ near Ridge B/C (Alley and Bentley, 1988) and $60 \mathrm{~mW} \mathrm{~m}^{-2}$ at the deep borehole drilled near Byrd Station (Rose, 1979). The sensitivity of basal melting is such that a change in $G$ by $10 \mathrm{~mW} \mathrm{~m}^{-2}$ yields a corresponding change in melt rate of $1 \mathrm{~mm} \mathrm{a}^{-1}$, which is small $(<10 \%)$ relative to the mean melt rates we estimate for this region. Some indirect geophysical estimates of geothermal fluxes in West Antarctica yield significantly higher values of $G$ (median $\sim 100 \mathrm{~W} \mathrm{~m}^{-2}$ with a range of about $50-150 \mathrm{~W} \mathrm{~m}^{-2}$ ), but their veracity has not been confirmed by direct observational data (Shapiro and Ritzwoller, 2004).

The basal shear heating term, $\tau_{\mathrm{b}} U_{\mathrm{b}}$, encompasses all heating at the bed due to the flow of the overlying ice, and is assumed here to be valid for both sliding across an 'immobile' plastic-till slip surface (i.e. failure at the yield stress within a very thin layer near the ice/bed interface) and distributed shear deformation within a viscous layer of finite thickness. We obtain the basal shear stress from the inversions described below. While the data shown in Figure 1 provide the surface velocity, the melt rate calculations require basal velocity, $U_{\mathrm{b}}$. At the ice-stream nodes, there is little internal deformation, so we assume $U_{\mathrm{b}} \approx U_{\mathrm{s}}$. Where the bed is strong beneath the ice sheet and some fast-flowing regions, internal deformation can make a significant contribution so that $U_{\mathrm{s}}$ is much greater than $U_{\mathrm{b}}$. 
To compensate for this, we estimate the speed due to internal deformation for each melted node (Paterson, 1994) and subtract it from $U_{\mathrm{s}}$ to estimate $U_{\mathrm{b}}$. Since we use $\tau_{\mathrm{b}}$ to compute the deformation velocity, this correction only has a significant effect in the regions where the bed is strong.

\subsection{Coupled ice-stream/ice-shelf model}

The equations that approximate large-scale flow over a weak-bedded ice stream or a floating ice shelf are (MacAyeal, 1989)

$$
\begin{aligned}
& \frac{\partial}{\partial x}\left[2 \nu H\left(2 \frac{\partial u}{\partial x}+\frac{\partial v}{\partial y}\right)\right]+\frac{\partial}{\partial y}\left[\nu H\left(\frac{\partial u}{\partial y}+\frac{\partial v}{\partial x}\right)\right]-\tau_{\mathrm{b}, x} \\
& -\rho_{\mathrm{i}} g H \frac{\partial z_{\mathrm{s}}}{\partial x}=0 \\
& \frac{\partial}{\partial y}\left[2 \nu H\left(2 \frac{\partial v}{\partial y}+\frac{\partial u}{\partial x}\right)\right]+\frac{\partial}{\partial x}\left[\nu H\left(\frac{\partial u}{\partial y}+\frac{\partial v}{\partial x}\right)\right]-\tau_{\mathrm{b}, y} \\
& -\rho_{\mathrm{i}} g H \frac{\partial z_{\mathrm{s}}}{\partial y}=0
\end{aligned}
$$

where $x$ and $y$ are the Cartesian coordinates defining the horizontal plane, $u$ and $v$ are the $x$ and $y$ components of velocity, $\rho_{\mathrm{i}}$ is the density of ice, $g$ is the acceleration due to gravity, $z_{\mathrm{s}}$ is the surface elevation, $H$ is the ice thickness, $\tau_{\mathrm{b}, x}$ and $\tau_{\mathrm{b}, y}$ are the components of the basal shear stress, and $\nu$ is the effective viscosity given by

$$
\nu=\frac{E^{-\frac{1}{n}} B}{2\left[\left(\frac{\partial u}{\partial x}\right)^{2}+\left(\frac{\partial v}{\partial y}\right)^{2}+\frac{1}{4}\left(\frac{\partial u}{\partial y}+\frac{\partial v}{\partial x}\right)^{2}+\frac{\partial u}{\partial x} \frac{\partial v}{\partial y}\right]^{\frac{n-1}{2 n}}} .
$$

The rate factor, $B$, and exponent, $n$, are from Glen's flow law with an enhancment factor $E$ (Paterson, 1994), which is equal to 1 in all our experiments. We solve these equations using finite-element methods similar to those described by MacAyeal (1989).

The model's governing stress-balance equations above include both basal drag and deviatoric stresses acting in the horizontal plane as a means to balance the driving stress. These equations are most applicable when vertical shear is small and ice flow is dominated by basal sliding or bed deformation. The model still produces reasonable results, however, in cases where there is significant deformation, but sliding still dominates (Payne and others, 2004).

In the case of a floating ice shelf, the basal shear stress terms are zero. For grounded ice, we use a general power sliding law of the form (Paterson, 1994)

$$
\begin{aligned}
\tau_{\mathrm{b}, x} & =\beta_{m}^{2}\left(u^{2}+v^{2}\right)^{\frac{1}{2}\left(\frac{1}{m}-1\right)} u \\
\tau_{\mathrm{b}, y} & =\beta_{m}^{2}\left(u^{2}+v^{2}\right)^{\frac{1}{2}\left(\frac{1}{m}-1\right)} v
\end{aligned}
$$

where the coefficent, $\beta_{m^{\prime}}$ is squared to ensure a nonnegative value in the inversion process. Lacking detailed knowledge of effective pressure at the bed, we have subsumed its effect into the coefficient, $\beta_{m}$, which we determine via a model inversion. If $m=1$, these equations correspond to a linear-viscous deforming-bed model (MacAyeal, 1992), which has been used in previous model studies of Pine Island Glacier (Schmeltz and others, 2002; Payne and others, 2004). Depending on basal conditions, values of $m=2$ or 3 are commonly used to model glacier sliding over a hard bed (Paterson, 1994).

Studies of till rheology, primarily involving actual till samples, suggest a non-linear relationship between basal shear stress and velocity (Kamb, 1991; Tulaczyk and others, 2000a; Kamb, 2001). Based on these results suggesting a plastic rheology, an alternate parameterization for the basal shear stress is given by (Joughin and others, 2004a)

$$
\begin{aligned}
& \tau_{\mathrm{b}, x}=\alpha^{2}\left(u^{2}+v^{2}\right)^{-\frac{1}{2}} u \\
& \tau_{\mathrm{b}, y}=\alpha^{2}\left(u^{2}+v^{2}\right)^{-\frac{1}{2}} v
\end{aligned}
$$

where direction is determined by the velocity, and the speedindependent magnitude of the basal shear stress is determined by $\alpha^{2}$. In this parameterization, we assume the till is always in plastic failure (i.e. failure once the basal shear stress reaches the yield stress), so the magnitude of the shear stress is independent of speed (Tulaczyk and others, 2000a).

Using an appropriate specification of the basal shear stress and ice rheology, the velocity of the coupled ice-stream/ ice-shelf system can be solved numerically using Equation (4). Either dynamic or kinematic boundary conditions are needed to solve these equations. In this study, we use kinematic boundary conditions to specify the velocity (e.g. Fig. 1) on regions of the boundary not immediately adjacent to the ocean. For the forward experiments described below, at the floating ice front, we employ a dynamic boundary condition, which is given by (MacAyeal and others, 1996)

$$
\begin{aligned}
& 2 \nu H\left(2 \frac{\partial u}{\partial x}+\frac{\partial v}{\partial y}\right) n_{x}+\left[\nu H\left(\frac{\partial u}{\partial y}+\frac{\partial v}{\partial x}\right)\right] n_{y}-\rho g \frac{H z_{s}}{2} n_{x}=0 \\
& 2 \nu H\left(2 \frac{\partial v}{\partial y}+\frac{\partial u}{\partial x}\right) n_{y}+\left[\nu H\left(\frac{\partial u}{\partial y}+\frac{\partial v}{\partial x}\right)\right] n_{x}-\rho g \frac{H z_{s}}{2} n_{y}=0
\end{aligned}
$$

where $n_{x}$ and $n_{y}$ are the components of the outward-pointing unit vector normal (in the horizontal plane) to the ice front. While it was simpler to employ the kinematic condition at the floating ice front for the inversion, the dynamic boundary condition is needed in the forward experiment to allow the speed at the front to vary in response to the simulated ungrounding. The kinematic conditions for the rest of the domain boundary are applied in regions well away from the ice stream (e.g. near divides) where the velocity should be unaffected by the ungrounding.

\subsection{Inversion for basal shear stress and flow-law parameter}

We invert the forward ice-stream model given by Equation (4) to find the basal shear stress that minimizes the misfit between the model-derived and observed velocities. This inversion relies on 'adjoint-trajectory methods' (MacAyeal, 1992, 1993), which are related to optimal control theory. With this method, an 'adjoint-trajectory' version of the model is created to develop an automatic and objective means of evaluating a 'cost function' (i.e. least-squares misfit between the modelled and observed velocity) as it varies with changes in the undetermined basal shear stress. As with many models, the ice-stream equations are 'self-adjoint', so little modification of the forward model code is needed to solve the inverse problem. Similar methods have been used successfully to study the basal shear stress field of several other West Antarctic ice streams (MacAyeal and others, 1995; Joughin and others, 2001, 2004a) and the Northeast Greenland Ice Stream' (Joughin and others, 2001).

We can apply the inversion procedure to either a linearviscous model given by Equation (6) with $m=1$, or a plastic-bed model given by Equation (7). Because force balance is achieved regardless of the assumed bed model, 

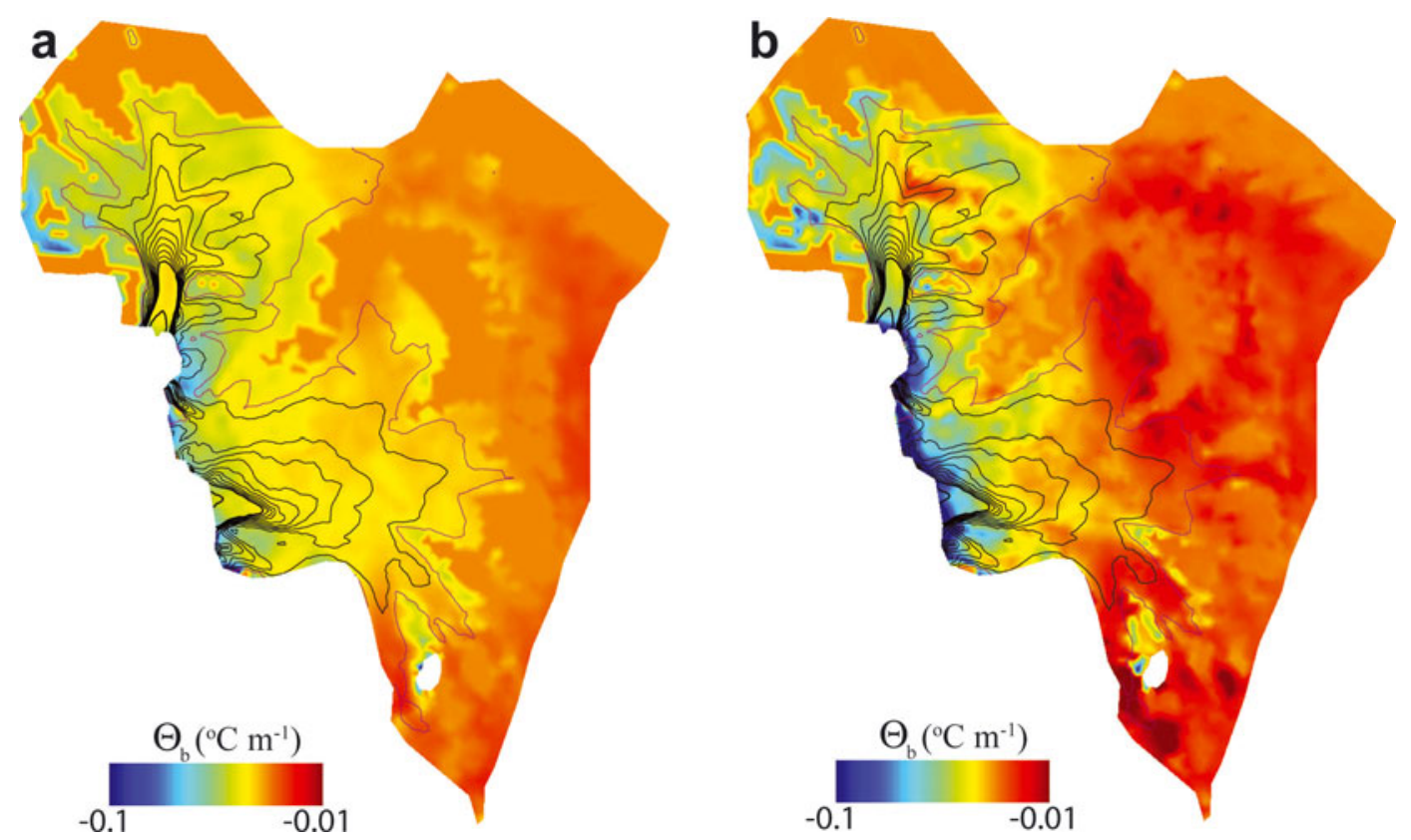

Fig. 3. Modelled basal temperature gradient (a) neglecting horizontal advection and (b) including horizontal advection. Glacier extents are indicated by the contours of glacier speed: $50 \mathrm{~m} \mathrm{a}^{-1}$ contour (purple), $100 \mathrm{~m} \mathrm{a}^{-1}$ contours up to $900 \mathrm{ma}^{-1}$ (thin black), and $1000 \mathrm{ma}^{-1}$ contours (thick black).

the inversion results alone cannot determine the most appropriate bed model.

The Glen's flow-law coefficient, $B$, in Equation (5) can also be inverted for using similar methods (Larour and others, 2005). An inversion for both parameters, however, is under-constrained, leading to non-unique results. As a result, for grounded ice we invert only for the basal shear stress, and we determine $B$ using the results from our temperature model and the temperature-dependent relation for $B$ given by Paterson (1994). This means that the inversion may introduce errors in the basal shear stress distribution that compensate for errors in our assumed values for $B$, thickness and surface slope in order to achieve the least model-data mismatch. On the floating ice the basal shear stress is fixed at zero, allowing us to invert solely for $B$ (in a strict sense $E^{-1 / n} B$ ) using kinematic boundary conditions on all lateral boundaries. It is important to note that while we are solving for the rheological parameter $B$, the value determined may include non-rheological effects such as strong rifting and crevassing that contributes to shear-margin weakening (Vieli and others, 2006).

\section{RESULTS}

We performed several model experiments to determine basal conditions beneath Pine Island and Thwaites Glaciers, which are described next.

\subsection{Temperature}

Using the present-day velocity and thickness distributions and allowing only the temperature to evolve, we ran the temperature model given by Equation (1) for $30 \mathrm{ka}$ to achieve a steady state. In this process, we neglected the influence of temporal changes in surface temperature, accumulation rate (vertical velocity), ice-sheet geometry and ice velocity over this period. The relatively rapid convergence likely can be attributed to our initialization with the vertical advection solution (Joughin and others, 2003a). Because the latter half of this $30 \mathrm{ka}$ interval falls within the Holocene, it is subject to relatively stable surface temperatures, similar to the present day. Figure 3 shows the final basal temperature gradient from the model, and the temperature gradient for the vertical-advection-only model used to initialize the solution.

Our lack of detailed surface temperature history somewhat limits the accuracy of the results. A more limiting factor may be that the current accumulation rate in this region is poorly known, with errors potentially as large as $100 \%$ (Van den Broeke and others, 2006). Finally, the flow speed of Pine Island is actively evolving, and speeds on other glaciers may also have changed over time. Despite similar limitations for the Siple Coast ice streams, our model produced relatively close agreement with measured borehole temperature profiles from that region (Joughin and others, 2004b). No such temperature profiles, however, are available for the Pine Island/Thwaites Glacier region.

Figure 3 illustrates the general pattern of the basal temperature gradient, which determines how rapidly heat is conducted away from the bed. As expected, even with only vertical advection, the temperature gradient is shallower in the deep subglacial troughs. Comparison of Figure $3 \mathrm{a}$ and Figure $3 \mathrm{~b}$ illustrates that horizontal advection has a strong effect on the basal temperature gradient. In areas of convergent flow, where the ice stretches vertically and thickens along flow as it enters the deep main trunks of the glaciers, the magnitudes of the temperature gradients are much smaller than farther upstream. In contrast, as ice is stretched thinner where the troughs shallow near the coast, the temperature gradient steepens substantially relative to the vertical-advection-only results.

\subsection{Melt rates}

Figure 4 shows our modelled estimates of basal melt, which vary over a wide range. Over much of the area near the grounding lines of Pine Island and Thwaites Glaciers, where the color table saturates $\left(>0.1 \mathrm{~m} \mathrm{a}^{-1}\right)$, the melt rate reaches or 
exceeds $0.4 \mathrm{ma}^{-1}$. In areas shaded gray, the ice is either frozen to the bed (slower-moving regions outside the main trunk), or the melt rate is negative, indicating basal freeze-on at rates of up to about $5 \mathrm{~mm} \mathrm{a}^{-1}$ (faster-moving areas). There are two such areas on Pine Island Glacier's main trunk, where the weak bed provides insufficient frictional heating to generate melt, allowing freeze-on to occur. In contrast, there is melting beneath the entire fast-moving area of Thwaites Glacier.

The modelled drainage basins of Pine Island and Thwaites Glaciers are nearly equal in size, with areas of 184000 and $189000 \mathrm{~km}^{2}$, respectively. The annual basal melt volume for the Pine Island Glacier catchment is $1.7 \mathrm{~km}^{3} \mathrm{a}^{-1}$, which produces a basin-wide average rate of $9.1 \mathrm{~mm} \mathrm{a}^{-1}$. The areal extent of the high-melt region is larger for Thwaites Glacier, yielding nearly twice as much melt at $3.5 \mathrm{~km}^{3} \mathrm{a}^{-1}$ for a basin-wide average melt rate of $18.7 \mathrm{~mm} \mathrm{a}^{-1}$.

The majority of the melt (94\%) for both catchments is from areas with fast flow $\left(>50 \mathrm{~m} \mathrm{a}^{-1}\right)$. Basal shear heating dominates in these regions, so the estimates are relatively insensitive to the geothermal heat flux or the basal temperature gradient. In slow-moving areas, our results show there are large regions with a thawed bed where melt occurs. Figure 3 indicates the melt in these regions is sensitive to the effect of horizontal advection in our estimates of temperature; there would be substantially less interior melting if only vertical advection were considered. The melt rates over much of this area are in the range $1-5 \mathrm{~mm} \mathrm{a}^{-1}$, which is comparable to the uncertainty caused by errors in the geothermal heat flux. One such area is at the upper edge of the Thwaites catchment, where we estimate basal melt rates of $2 \mathrm{~mm} \mathrm{a}^{-1}$, $30 \mathrm{~km}$ from the West Antarctic Ice Sheet (WAIS) Divide drill site (see red star in Fig. 1 for location). Earlier estimates from the other side of the divide also indicate basal melt (Joughin and others, 2004b). While the uncertainty in the geothermal heat flux is large enough to allow for a frozen bed at this location, there is an onset of relatively faster flow in a tributary of Thwaites Glacier about $100 \mathrm{~km}$ from the drill site, which suggests a melted bed.

\subsection{Basal shear stress}

We inverted the ice-stream model for the parameters that determine basal shear stress beneath the fast-moving areas of both glaciers using the methods described above. For the finite-element mesh, we varied the node spacing from $\sim 1.5 \mathrm{~km}$ in fast-moving areas to $\sim 5 \mathrm{~km}$ in slower-moving areas. In the following discussion we refer to the bed as being 'strong' where the driving stress is large $(>40 \mathrm{kPa})$ and roughly equal to the basal shear stress. It is important to note that the inversion is not strictly applicable in strongbedded regions, so the inversion results serve more as a qualitative indicator of bed character in these areas rather than providing quantitatively accurate values (MacAyeal, 1993; MacAyeal and others, 1995). We use the term 'weak' to describe the regions where the basal shear stress is small $(<40 \mathrm{kPa})$ and likely does not support the full driving stress.

Figure 5 shows basal shear stress for Pine Island Glacier obtained using a viscous-bed model $(m=1)$. Similar results (not shown) are obtained with a plastic-bed model since force-balance is achieved with either model. Also shown is an image of the same area from the moderate-resolution imaging spectroradiometer (MODIS) Mosaic of Antarctica

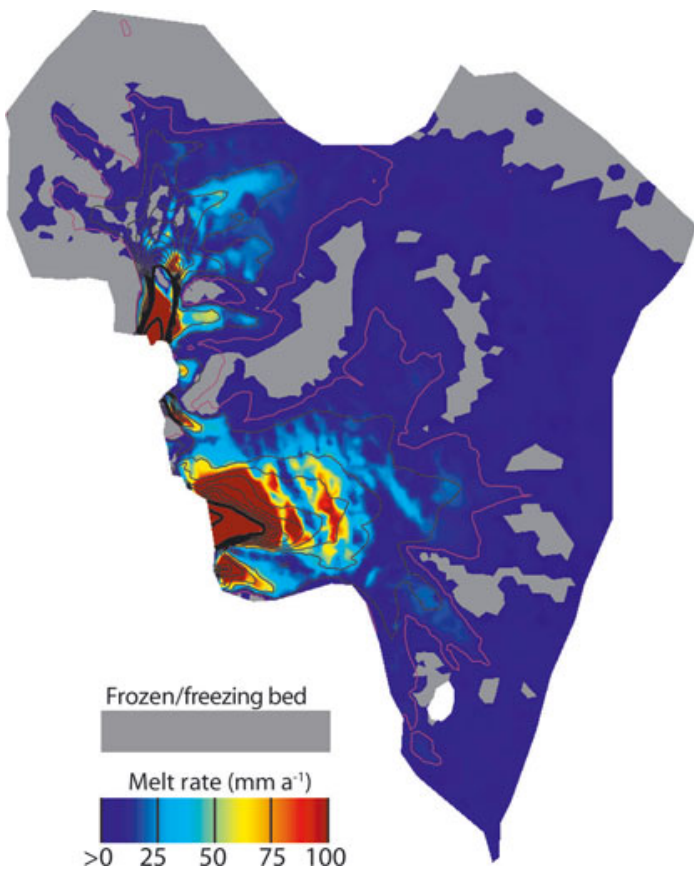

Fig. 4. Basal melt rates for Pine Island and Thwaites Glaciers. Glacier extents are indicated by the contours of glacier speed: $50 \mathrm{~m} \mathrm{a}^{-1}$ contour (purple), $100 \mathrm{~m} \mathrm{a}^{-1}$ contours up to $900 \mathrm{~m} \mathrm{a}^{-1}$ (thin black), and $1000 \mathrm{~m} \mathrm{a}^{-1}$ contours (thick black). Although the modelled values may be much higher, the color table saturates at $100 \mathrm{~mm} \mathrm{a}^{-1}$ to allow variation in regions of low melt to be distinguished.

(MOA), with the contrast stretched to reveal subtle features in the surface topography (Scambos and others, 2007).

The inversion reveals a weak area just above the Pine Island grounding line, in the relatively flat area, near flotation, that was earlier identified as an 'ice plain' (Corr and others, 2001). The surface slope steepens sharply inland of this region, producing larger driving stress (100-200 kPa), which is resisted locally by the strong bed in this region. Above the steep area, the surface on the main trunk of the glacier and its tributaries flattens out, yielding driving stresses of $10-50 \mathrm{kPa}$. Over large areas on this trunk, which extends $>150 \mathrm{~km}$ inland of the strong-bedded region, the bed is weak, offering virtually no resistance $(<2 \mathrm{kPa})$. Instead, the driving stress in this region must be balanced by longitudinal and lateral stress gradients that transfer the stress to isolated 'sticky spots', to areas farther upstream and to the bed near the ice-stream margins. This result is consistent with earlier inferences of a weak bed in this region based on geometry (Joughin and others, 2003b), and analytical (Thomas and others, 2004b) and numerical models (Vieli and Payne, 2003; Payne and others, 2004). A large band of arcuate crevasses is visible in synthetic aperture radar (SAR) imagery (not shown) (Rabus and Lang, 2003) at the location marked AC in Figure 5, which suggests strong stretching as longitudinal stress gradients compensate for the weak bed. The regions where the shear stress estimates are low correspond to areas in the MOA image with the appearance of more gently undulating surface topography and where flow stripes are visible. This is consistent with the presence of large weakbedded areas (Gudmundsson and others, 1998).

Figure 6 shows the estimated basal shear stress for Thwaites Glacier. The results indicate a band of strong bed that extends inland for about $80 \mathrm{~km}$ from the grounding line. Above this region, there are isolated pockets of weak bed 

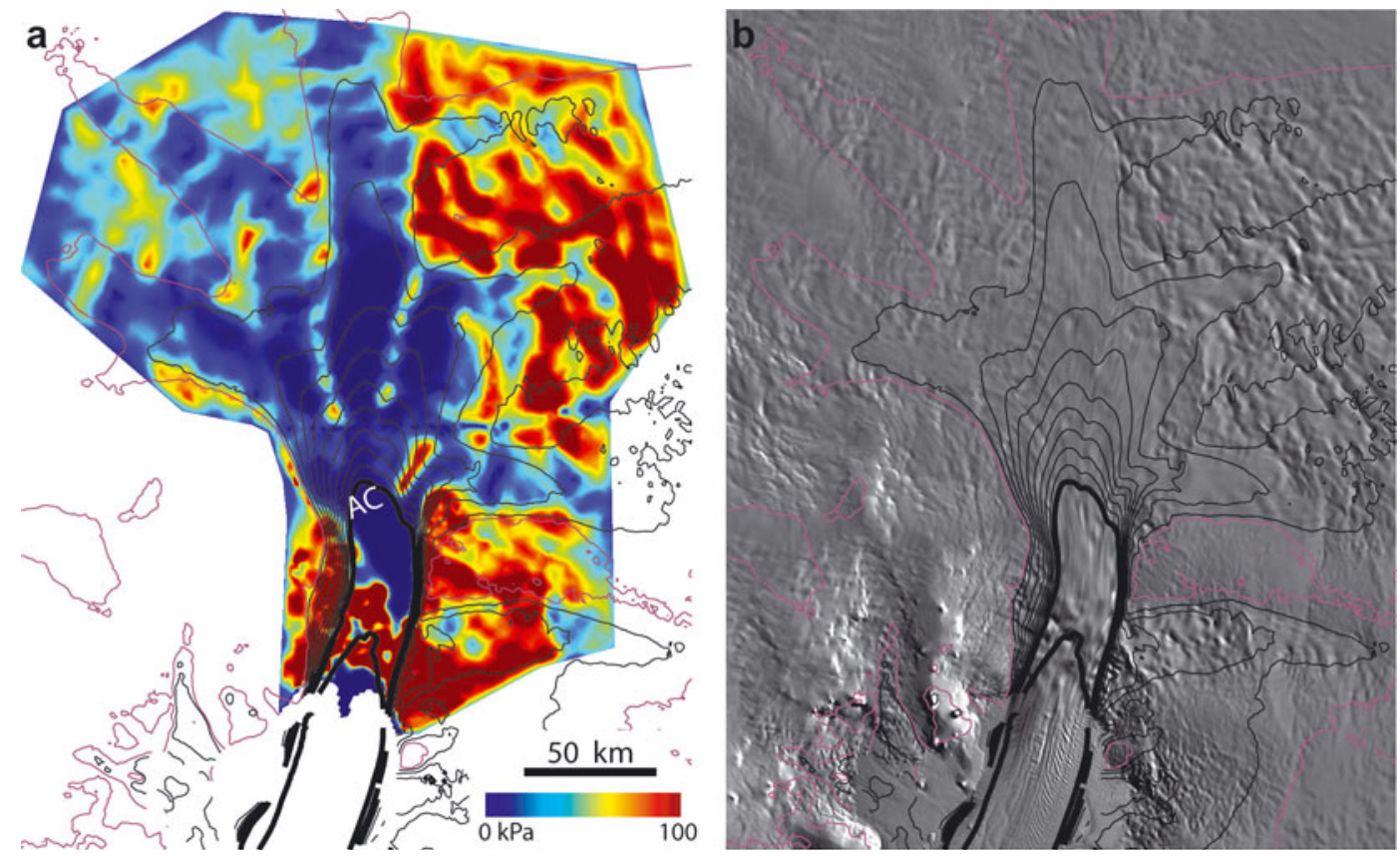

Fig. 5. (a) Inversion of basal shear stress calculated using viscous-bed model for Pine Island Glacier and (b) MOA image. Glacier extents are indicated by the contours of glacier speed: $50 \mathrm{ma}^{-1}$ contour (purple), $100 \mathrm{~m} \mathrm{a}^{-1}$ contours up to $900 \mathrm{ma}^{-1}$ (thin black), and $1000 \mathrm{ma}^{-1}$ contours (thick black). The position of the arcuate crevasses discussed in the text is marked 'AC'.

that generally lie between bands of stronger bed. These weak areas likely lie in depressions in the bed topography and may represent areas where till has accumulated as opposed to local highs where it may have been preferentially eroded. These weak areas also agree well with smooth regions visible in the MOA imagery, which suggest a smoother, flatter, ice surface consistent with a weak underlying bed. Relative to Pine Island Glacier, the weak areas seem aligned more across flow than along flow, and there appears to be much more surrounding strong-bedded area, indicating a bed that is substantially stronger on average. This stronger bed likely allows the much steeper surface and higher elevations for the active parts of Thwaites Glacier in comparison with the more drawn-down profile of the upstream regions of Pine Island Glacier.

\subsection{Forward model experiments}

As noted earlier, any plausible bed (sliding) model has sufficient degrees of freedom so that it can be inverted to produce a basal shear-stress estimate that achieves a balance of forces consistent with the observed velocity field. To determine whether a power sliding law, plastic rheology or alternative bed model is the most appropriate, observations of how the glacier responds to perturbations in this force balance are required. Here we use the forward ice-stream/ice-shelf model (Equations (4) and (5)) and perturb the modelled grounding line to evaluate the dynamic (diagnostic model) response for different bed models. The results of these experiments are then compared with observed changes. Earlier similar model experiments showed that small changes at the grounding line can produce substantial speed-up far inland of the grounding line, but these studies employed only a linear-viscous bed model (Schmeltz and others, 2002; Payne and others, 2004; Dupont and Alley, 2005).

In our experiments, we use the bed models given by Equations (6) and (7). With $m=1$ in Equation (6), we obtain a linear-viscous model. Other studies often employ sliding laws with values of $m=2$ or 3 (Paterson, 1994). For simplicity, we used a single value of $m=3$.

The third model we consider is the plastic-bed model. In areas where the bed consists of weak till, a plastic-till rheology is often considered appropriate (Kamb, 1991; Tulaczyk and others, 2000a). Recent theoretical results also suggest that hard-bedded sliding can exhibit similar behaviour, even leading to diminishing resistance with increasing speed (e.g. velocity weakening) in areas with low effective pressure and high sliding rates (Schoof, 2005). If this conjecture is correct, then of the models we consider, the plastic model should most closely approximate rapid sliding over a hard bed, since it does not increase without bound. We applied the plastic-bed model only on the fastmoving parts of the ice stream. For the slower-moving areas in the plastic-bed experiments, we used Equation (6) with $m=3$, which allowed basal resistance to increase in areas outside the glacier to maintain a force balance.

To determine the parameters for the forward model, we simultaneously inverted for the basal shear stress beneath grounded ice and for the flow-law parameter $B$ on floating ice. Using these values, the root-mean-square difference between the InSAR velocity (1996) and our forward reference model (Fig. 7) was $25 \mathrm{~m} \mathrm{a}^{-1}$ and $21 \mathrm{~m} \mathrm{a}^{-1}$ for the linear-viscous and plastic inversions, respectively. Since we used kinematic boundary conditions for the inversion, differences increased slightly when we used a dynamic boundary condition (Equation (8)) along the front of the ice shelf in the forward model. Since we did not implement an explicit inversion for $m=3$, we used the $m=1$ shear stress solution to solve Equation (6) for $\beta_{3}$. As a result, the reference cases for the three bed models shown in Figure 8 differ slightly in speed, but all of them compare well with the InSAR speeds (Joughin and others, 2003b).

In a manner similar to earlier experiments (Schmeltz and others, 2002; Payne and others, 2004), we reduced the basal 

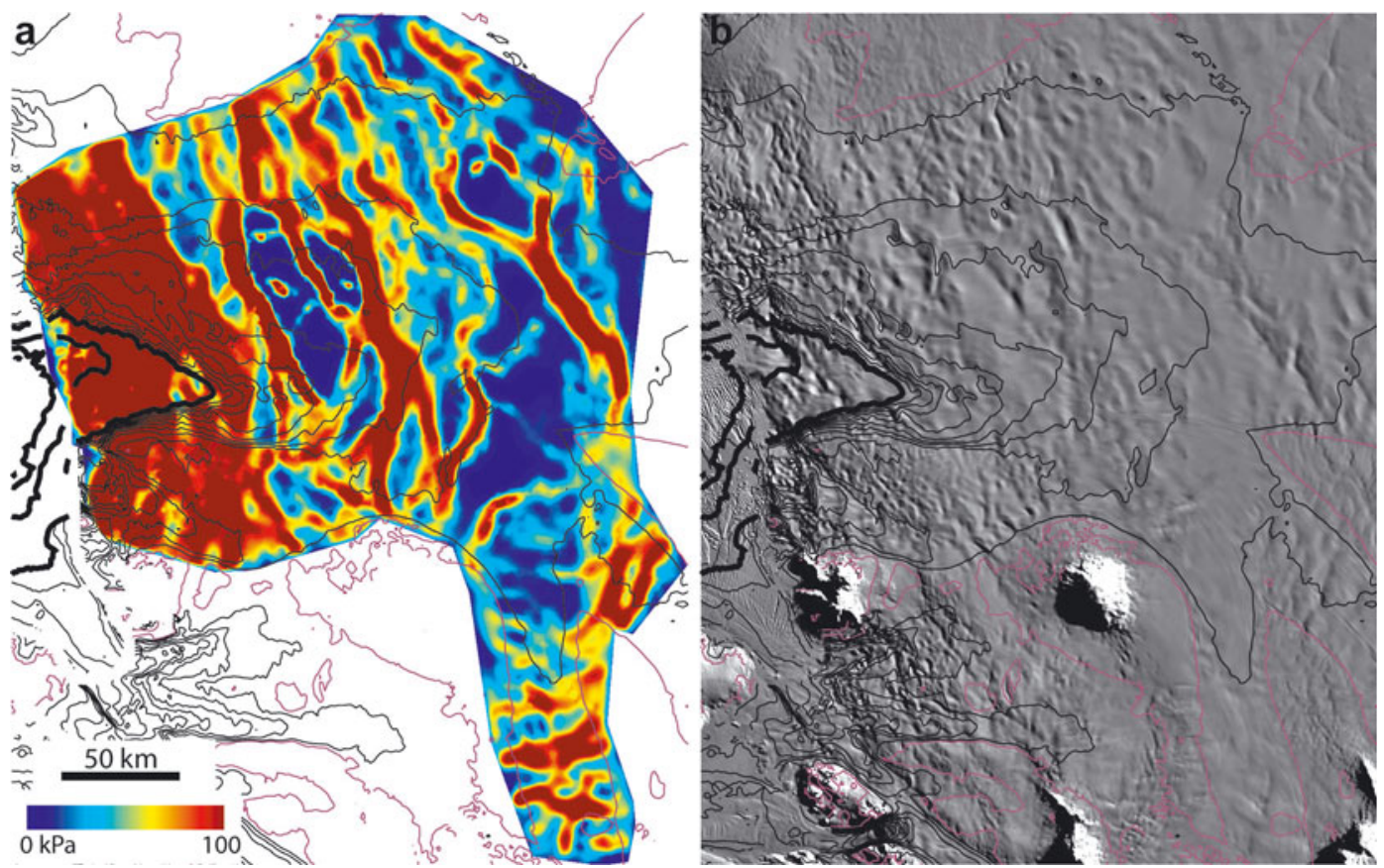

Fig. 6. (a) Inversion of basal shear stress calculated using viscous bed model for Thwaites Glacier and (b) MOA image. Glacier extents are indicated by the contours of glacier speed: $50 \mathrm{~m} \mathrm{a}^{-1}$ contour (purple), $100 \mathrm{~m} \mathrm{a}^{-1}$ contours up to $900 \mathrm{ma}^{-1}$ (thin black), and $1000 \mathrm{ma}$ contours (thick black).

resistance in areas near the grounding line to zero in order to approximate a grounding-line retreat (Fig. 7 inset). Since it does not actually unground the ice, this produces an area that is steeper and thicker than it would be if it had gradually evolved toward flotation. For Pine Island Glacier, this likely is a reasonable approximation of grounding-line retreat since the ice in this area is near flotation and relatively flat (Corr and others, 2001). We performed experiments with mean grounding line retreats of 2.9 and $5.2 \mathrm{~km}$ as shown in Figure 8a. Since the retreat is not uniform across the width of the glacier, we computed the retreat distance as the ungrounded area divided by the glacier width.

Figure $8 \mathrm{~b}$ shows the speed-ups caused by the specified grounding line retreat expressed as a percentage of the reference-model speed. For the $2.9 \mathrm{~km}$ retreat experiment, basal resistance was zeroed over an area of $111 \mathrm{~km}^{2}$ from a prior mean basal shear stress of $42 \mathrm{kPa}$. This produced maximum speed-ups near the grounding line from about $4.5 \%$ for the linear-viscous case to just over $16 \%$ for the plastic bed. These speed-ups are comparable in magnitude to the actual increase in speed from 1992 to 2000 (Rignot and others, 2002). For the $5.2 \mathrm{~km}$ modelled retreat, the ungrounded area $\left(203 \mathrm{~km}^{2}\right)$ was just under twice the size with a prior mean basal shear stress of $50 \mathrm{kPa}$. This produced maximum speed-ups of $11 \%$ and $37 \%$ for the linear-viscous and plastic-bed models, respectively. In both cases, the $m=3$ sliding law produced a response about $50 \%$ larger than the linear-viscous case.

In addition to the increased sensitivity near the grounding line, both the $m=3$ and plastic-bed models produced speedup substantially farther inland than the linear-viscous model (Schmeltz and others, 2002; Payne and others, 2004). For the linear-viscous bed, force balance was restored largely by increased basal resistance within about $50 \mathrm{~km}$ of the grounding line. For $m=3$, basal resistance cannot increase within the same distance of the grounding line, so the speed-up extends farther inland. For the plastic bed, force balance can only be restored by lateral and longitudinal stress gradients that distribute the resistance lost near the grounding line to the non-plastic bed areas outside the fast-moving regions. As a consequence, the speed-up extends much farther inland, up to distances of $>200 \mathrm{~km}$ from the grounding line.

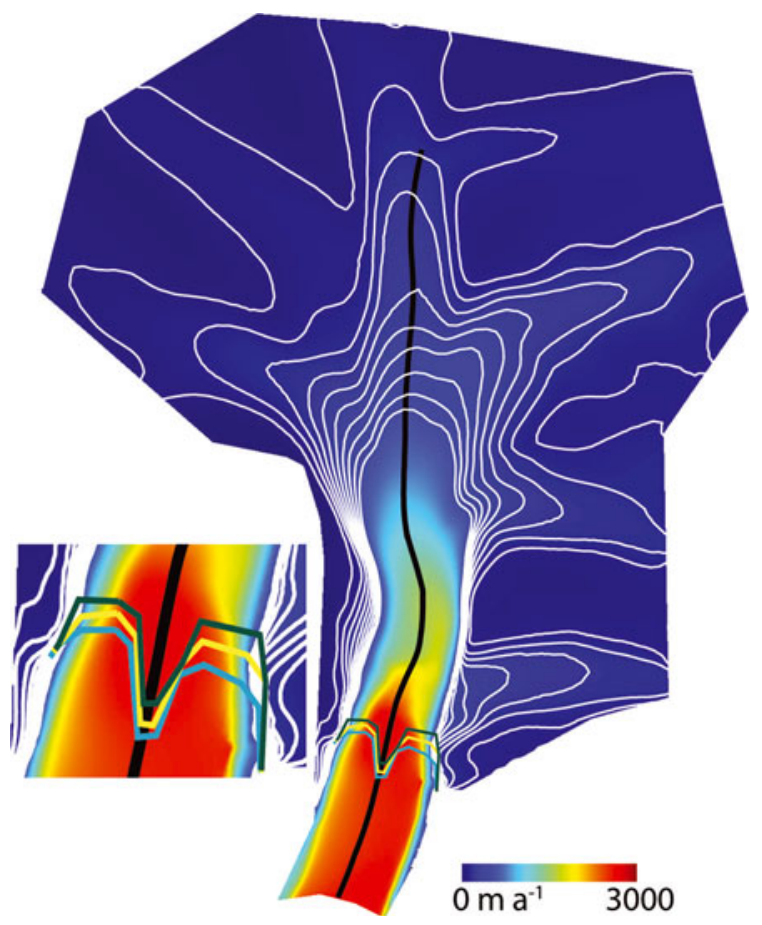

Fig. 7. Reference model speed (color) for the linear-viscous model. Speed is also shown with $50 \mathrm{~m} \mathrm{a}^{-1}$ white contours for values up to $500 \mathrm{~m} \mathrm{a}^{-1}$. Inset shows the grounding line at the reference position (white) and after mean retreats of 2.9 and $5.2 \mathrm{~km}$. 

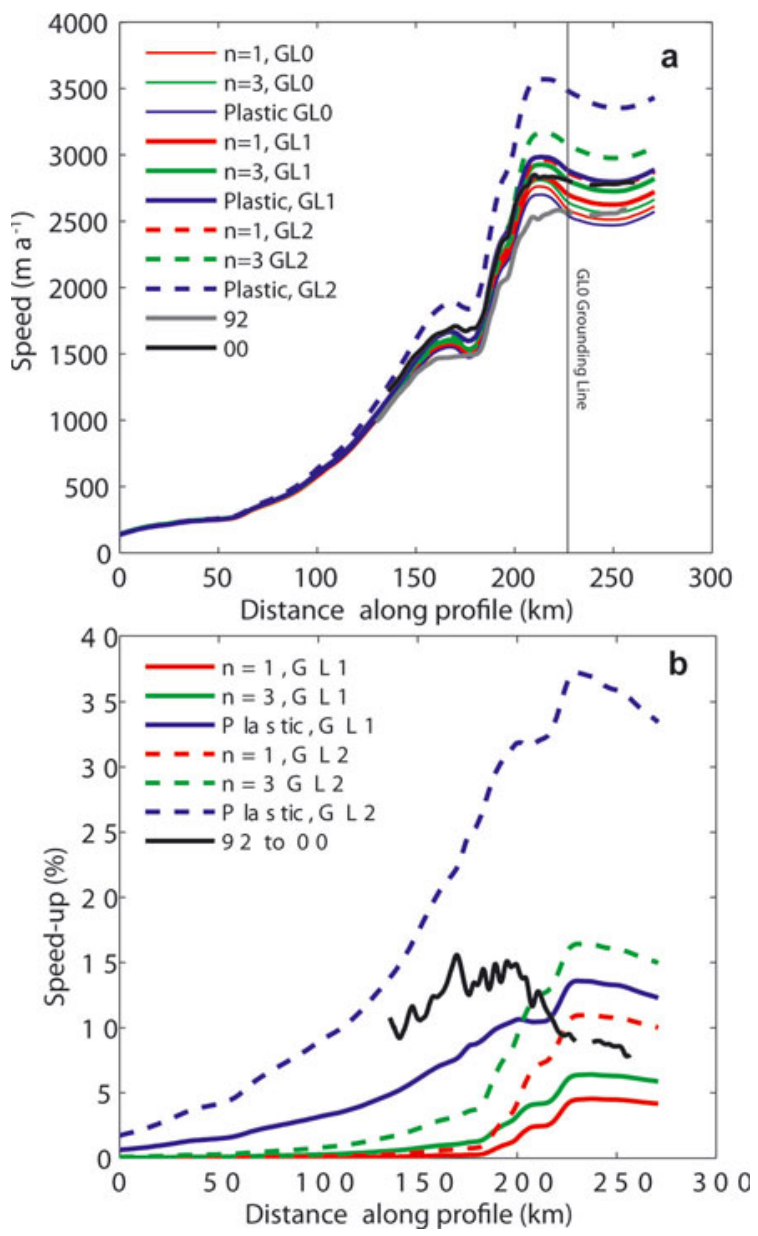

Fig. 8. (a) Modelled speed using different bed models (color) for the reference models (GLO) and grounding line retreats of $2.9(\mathrm{GL} 1)$ and 5.2 (GL2) km. Also shown are InSAR-determined speeds from 1992 and 2000. (b) Speed-up expressed as percentage of the reference model speed (GL0) for grounding line retreat of 2.9 (GL1) and 5.2 (GL2) km.

\section{DISCUSSION}

\subsection{Melt rates}

The basal steady-state temperature gradient estimates show that the inclusion of horizontal advection in the model has a substantial effect. As in the case of the Ross ice streams (Joughin and others, 2004b), the basal temperature gradient becomes more negative in the fast-moving areas where ice thins toward the grounding line. There are several such areas beneath the fast-flowing sections of the Ross ice streams where the weak basal till produces too little frictional heating to avoid basal freezing (Hulbe and Fahnestock, 2004; Joughin and others, 2004b). For these areas, continued basal lubrication may rely on transport of water generated farther upstream in tributaries, where higher basal shear stresses and shallower basal temperature gradients favour greater melt (e.g. Parizek and others, 2003). In contrast, for Pine Island and Thwaites Glaciers, although the temperature gradient is not conducive to melt, the rapid speeds and high basal shear stress produce strong melt $\left(>0.1 \mathrm{~m} \mathrm{a}^{-1}\right)$ near the grounding line. As a result, these high melt rates yield basin-wide average melt rates for Pine Island and Thwaites Glaciers that are roughly 4.5 times larger than for the Ross ice streams.

Limited melt beneath weak-bedded ice streams can provide a thermal feedback whereby an ice stream thins and promotes basal freezing, eventually leading to icestream shutdown (Tulaczyk and others, 2000b; Bougamont and others, 2003a,b). This, along with subsequent reactivation of these ice streams, has led to significant flow variability in the Ross Sea section over the last millennium (Fahnestock and others, 2000). With the strong melt generated beneath both Thwaites and Pine Island Glaciers, it is unlikely that current or past variability can be attributed to such a feedback (Raymond, 2000). Furthermore, because melt due to basal shear heating is so large, it is unlikely that temporal fluctuations in geothermal heat flux due to nearby volcanic activity could explain recent changes.

Channels in crystalline bedrock are found on the sea floor in formerly glaciated regions within a few tens of kilometers of the present Pine Island Ice Shelf, which are believed to have been formed by abundant subglacial meltwater (Lowe and Anderson, 2003). They estimate relatively modest melt rates of $0.24-0.5 \mathrm{~km}^{3} \mathrm{a}^{-1}$ and conclude additional melt must originate farther upstream. Our basin-wide rate of $1.7 \mathrm{~km}^{3} \mathrm{a}^{-1}$ is considerably higher and almost entirely generated by strong melt $\left(\sim 0.1 \mathrm{~m} \mathrm{a}^{-1}\right)$ over fast-moving regions with a strong bed. These high-melt regions may correspond to regions of crystalline bedrock, similar to that where the channelized topography has been observed. If similar in magnitude to the rates estimated here, local melt in the channelized regions may have been sufficient to produce the observed features.

\subsection{Basal shear stress}

The basal shear stress beneath Pine Island and Thwaites Glaciers is characterized by areas of strong resistance near the grounding line, with patches of weak bed at locations farther inland. These weak areas are more limited for Thwaites Glacier, which may explain its steeper profile. In contrast, the extensive weak area along much of Pine Island Glacier's main trunk may account for its shallow slope and likely contributes to the relatively low elevation $(<1300 \mathrm{~m})$ of the divide between it and Rutford Ice Stream, which also has extensive weak areas (Vaughan and others, 2003; Joughin and others, 2006).

Observations from the sea floor in front of Pine Island Glacier reveal areas of exposed crystalline bedrock (Lowe and Anderson, 2003), likely similar in character to regions where we calculate high basal shear stress. In other areas near the front of the glacier, piston cores and other geophysical observations indicate areas covered by weak sediment deposits with shear strengths ranging from 1.0 to $6.9 \mathrm{kPa}$, which is consistent with the magnitudes of shear stresses for the weak areas we find farther inland. Thus, unlike the Ross ice streams, which tend to flow over large expanses of uniformly weak bed (Joughin and others, 2004a), our results and ship-borne observations reveal 'mixed' bed conditions, alternating between regions of low drag, almost certainly deforming sediments, and those providing greater basal resistance, possibly non-deforming sedimentary rock or even crystalline bedrock of the type identified by Lowe and Anderson (2003) on the nearby continental shelf. Over extensive areas near their respective grounding lines, both Pine Island and Thwaites Glaciers are presently grounded on a strong bed, suggesting they have retreated back over weak sediment-laden regions to positions of relative stability.

Although there are weak areas beneath Thwaites Glacier, these tend to be somewhat isolated and surrounded by nearby areas of relatively strong bed, which likely compensate for 
the weak regions and may promote some degree of stability. In contrast, there is a $>140 \mathrm{~km}$ long weak region extending up much of the length of Pine Island Glacier's main trunk. This region is 'buttressed' by the $\sim 40 \mathrm{~km}$ wide band of high basal shear stress located just above the grounding line, much of which is only a few tens to hundreds of meters above flotation. The results in Figure 8 along with those of earlier studies (Schmeltz and others, 2002; Payne and others, 2004; Thomas and others, 2004b) suggest that the glacier is extremely sensitive to even small changes in loss of this basal resistance. Such results are consistent with observations that this glacier has accelerated by $>40 \%$ between 1974 and 2006 (Joughin and others, 2003b; Rignot and others, 2008) as areas near the grounding line have thinned by $>1 \mathrm{ma}^{-1}$ (Shepherd and others, 2001), and the grounding line has retreated by several kilometers (Rignot, 1998). This retreat seems to be largely confined to the region near the grounding line where we infer a relatively weak bed. Thus, the basal shear-stress distribution shown in Figure 5 suggests the potential for a large instability if the ice continues to thin and retreat over this region, ungrounding ice from the strongbedded region that appears to be holding back ice from the weak-bedded interior.

\subsection{Bed model}

Our experiments (Fig. 8) reveal that in addition to the magnitude of the basal shear stress, the form of the bed model plays a large role in the modelled sensitivity of the glacier to changes in basal resistance near the grounding line, affecting both the magnitude and spatial scale of the response. While early studies suggested that a linear-viscous bed was appropriate for flow over weak till (Alley and others, 1986; Blankenship and others, 1986), more recent studies find that a perfectly plastic rheology is a better model (Kamb, 1991; Tulaczyk and others, 2000a). Furthermore, a linear-viscous bed model is not appropriate for sliding over bedrock (Paterson, 1994). Thus, it is likely that the linearviscous model, which yielded the least sensitivity in our experiments, is an inappropriate model and earlier studies based on this bed model likely underestimate the glacier's sensitivity to changes in basal resistance near the grounding line (Schmeltz and others, 2002; Payne and others, 2004).

Although a plastic-bed model may be appropriate for weak till, flow over a hard bedrock typically is represented by sliding laws of the form of Equation (6) with $m=2$ or $m=3$ (Paterson, 1994). Our results indicate that a sliding law with $m=3$ produces a substantially larger ( $~ 50 \%)$ speed-up that extends significantly farther inland than the response for a linear-viscous model to the simulated ungrounding. In addition to this nearly instantaneous response, prognostic ice-stream model studies suggest that the ensuing time-dependent response will propagate inland more rapidly as the degree of non-linearity in the bed model is increased (Price and others, 2008).

Theoretical work indicates that for a bed with bounded slopes, basal shear stress cannot increase without bound as it does in a power sliding law (Iken, 1981; Schoof, 2005). Instead, these theoretical studies suggest that for sliding at high speed and low effective pressure, resistance initially increases with speed, similar to that for power-law sliding, but reaches a peak after which it decreases with faster sliding. None of the models we used is equivalent to the sliding model proposed by Schoof (2005), but the plastic model has the characteristic that shear stress does not increase without bound as sliding speed increases. Because shear stress is fixed and does not decline, the plastic model is likely to be less sensitive to geometric changes that alter the force balance than the type of sliding law proposed by Schoof (2005). Hence, even with the plastic-bed model, our results may underestimate the glaciers' sensitivity to grounding-line retreat.

The extent of the simulated ungrounding in our model experiments is consistent with the magnitude of observed changes in grounding line position (Rignot, 1998). There is enough observational uncertainty to allow plausible adjustment of the modelled grounding line so that any of the three models can match the magnitude of speed-up in the neargrounding-line region. Only the modelled speed-up for the plastic bed is still appreciable at distances of $>200 \mathrm{~km}$ from the grounding line, which is consistent with the extent over which there is substantial thinning (Shepherd and others, 2002). Thus, with a plastic-bed or similar sliding law (Schoof, 2005), the direct response to a grounding line shift could produce thinning comparable to the observed magnitudes. This model also provides the best apparent agreement with the extent of the observed inland speed-up (Fig. 8b).

When considering the agreement between observed and modelled speed-up, it is important to consider the observations showing speed-up were acquired 8 years apart. Payne and others (2004) demonstrated how an initial speedup can steepen surface slopes and diffuse rapidly inland over the course of years or decades to produce inland thinning and speed-up over a much larger area than affected by the initial speed-up. This type of effect undoubtedly has some influence on the InSAR speeds shown in Figure 8. Thus, while the agreement between model and data suggests something approaching a plastic-like bed response, the results are far from definitive. Nevertheless, the agreement is close enough to clearly demonstrate at least the plausibility of this type of behaviour.

\section{SUMMARY}

Our results reveal that Pine Island and Thwaites Glaciers are underlain by regions of hard resistive bed and weak deforming bed. Both glaciers are primarily restrained by their hardbedded regions of resistive bed, which are tens of kilometers wide and located just above their respective grounding lines. Combined with the high speeds, these regions produce strong melt $\left(>0.1 \mathrm{~m} \mathrm{a}^{-1}\right)$, making it unlikely that these glaciers are subject to the kinds of thermal instabilities that affect the Ross ice streams as also suggested by Raymond (2000).

Many studies of sliding have been limited by the availability of data with which to test various sliding laws (Paterson, 1994). As glacier-wide observations of glacier speed-up (and slowdown) become available, we are better positioned to evaluate different parameterizations of basal resistance. Our results demonstrate that plastic or potentially even 'velocity-weakening' behaviour (Schoof, 2005) at high sliding speeds over a hard bed is no less plausible than more traditional power sliding laws (Paterson, 1994). Existing observations are insufficient to distinguish between competing models, but additional observations or the use of a timedependent model that includes the effect of evolving icesheet geometry may help to better constrain the appropriate bed model. Our results do show that even when the magnitude of the basal shear stress can be determined (e.g. MacAyeal and others, 1995), differences in the form of the 
bed model can produce large differences in sensitivity to relatively small perturbations near the grounding line.

By constraining ice-sheet models with data in the area of Antarctica currently experiencing the greatest mass loss (Shepherd and others, 2002; Rignot and others, 2008), we have produced a plausible set of regional estimates for basal conditions and englacial temperatures. These provide a set of boundary and initial conditions for future predictive modelling efforts, which we have not yet attempted. Using models tightly constrained by the observations of ice-sheet geometry and flow velocity provides an alternative approach to forward time-stepping a model through multiple glacial cycles in order to arrive at present-day conditions (e.g. Huybrechts and others, 2004). It is important to note that while we used the ice-stream equations given by Equation (4) (MacAyeal, 1989), we could have employed a similar approach with other flow models (Hindmarsh, 2004).

Finely gridded velocity, elevation, thickness and other datasets are continuing to become more readily available. As we transition from a dearth to a plethora of observations, new methodologies must be developed to integrate data and ice-sheet models to better understand the fundamental controls on ice-sheet flow and to improve predictive modelling efforts. Such efforts are critical to reducing the uncertainties related to ice dynamics highlighted by the most recent Intergovernmental Panel on Climate Change (Solomon and others, 2007).

\section{ACKNOWLEDGEMENTS}

NASA grants NNG05G009G and NNG06GG25G supported I.J.'s contribution. We acknowledge D.R. MacAyeal's generous support in providing early versions of ice-stream and inverse model code and his subsequent guidance. Comments by M. Maki, S. Price and two anonymous reviewers resulted in substantial improvement in the final manuscript.

\section{REFERENCES}

Alley, R.B. and C.R. Bentley. 1988. Ice-core analysis on the Siple Coast of West Antarctica. Ann. Glaciol., 11, 1-7.

Alley, R.B., D.D. Blankenship, C.R. Bentley and S.T. Rooney. 1986. Deformation of till beneath Ice Stream B, West Antarctica. Nature, 322(6074), 57-59.

Bamber, J.L., J.L. Gomez-Dans and J.A. Griggs. 2008. A new $1 \mathrm{~km}$ digital elevation model of the Antarctic derived from combined satellite radar and laser data - Part 1: data and methods. Cryos. Discuss., 2(5), 811-841

Blankenship, D.D., C.R. Bentley, S.T. Rooney and R.B. Alley. 1986. Seismic measurements reveal a saturated porous layer beneath an active Antarctic ice stream. Nature, 322(6074), 54-57.

Bougamont, M., S. Tulaczyk and I. Joughin. 2003a. Numerical investigations of the slow-down of Whillans Ice Stream, West Antarctica: is it shutting down like Ice Stream C? Ann. Glaciol., 37, 239-246.

Bougamont, M., S. Tulaczyk and I. Joughin. 2003b. Response of subglacial sediments to basal freeze-on: 2. Application in numerical modeling of the recent stoppage of Ice Stream C, West Antarctica. J. Geophys. Res., 108(B4), 2223. (10.1019/ 2002JB001936.)

Comiso, J.C. 1994. Surface temperatures in the polar regions from Nimbus 7 temperature humidity infrared radiometer. J. Geophys. Res., 99(C3), 5181-5200.
Comiso, J.C. 2000. Variability and trends in Antarctic surface temperatures from in situ and satellite infrared measurements. J. Climate, 13(10), 1674-1696.

Corr, H.F.J., C.S.M. Doake, A. Jenkins and D.G. Vaughan. 2001. Investigations of an 'ice plain' in the mouth of Pine Island Glacier, Antarctica. J. Glaciol., 47(156), 51-57.

Engelhardt, H. 2004. Ice temperature and high geothermal flux at Siple Dome, West Antarctica, from borehole measurements. J. Glaciol., 50(169), 251-256.

Fahnestock, M.A., T.A. Scambos, R.A. Bindschadler and G. Kvaran. 2000. A millennium of variable ice flow recorded by the Ross Ice Shelf, Antarctica. J. Glaciol., 46(155), 652-664.

Giovinetto, M.B. and H.J. Zwally. 2000. Spatial distribution of net surface accumulation on the Antarctic ice sheet. Ann. Glaciol., 31, 171-178.

Griggs, J.A. and J.L. Bamber. 2008. A new $1 \mathrm{~km}$ digital elevation model of Antarctica derived from combined radar and laser data - Part 2: validation and error estimates. Cryos. Discuss., 2(5), 843-872

Gudmundsson, G.H., C.F. Raymond and R. Bindschadler. 1998. The origin and longevity of flow stripes on Antarctic ice streams. Ann. Glaciol., 27, 145-152.

Hindmarsh, R.C.A. 2004. A numerical comparison of approximations to the Stokes equations used in ice sheet and glacier modeling. J. Geophys. Res., 109(F1), F01012. (10.1029/2003JF000065.)

Holt, J.W. and 8 others. 2007. New boundary conditions for the West Antarctic Ice Sheet: subglacial topography of the Thwaites and Smith glacier catchments. Geophys. Res. Lett., 33(9), L09502. (10.1029/2005GL025561.)

Hulbe, C.L. and M.A. Fahnestock. 2004. West Antarctic ice-stream discharge variability: mechanism, controls and pattern of grounding-line retreat. J. Glaciol., 50(171), 471-484.

Huybrechts, P., J. Gregory, I. Janssens and M. Wild. 2004. Modelling Antarctic and Greenland volume changes during the 20th and 21 st centuries forced by GCM time slice integrations. Global Planet. Change, 42(1-4), 83-105.

Iken, A. 1981. The effect of the subglacial water pressure on the sliding velocity of a glacier in an idealized numerical model. J. Glaciol., 27(97), 407-421.

Jacobs, S.S., H.H. Hellmer and A. Jenkins. 1996. Antarctic ice sheet melting in the southeast Pacific. Geophys. Res. Lett., 23(9), 957-960.

Joughin, I. 2002. Ice-sheet velocity mapping: a combined interferometric and speckle-tracking approach. Ann. Glaciol., 34, 195-201.

Joughin, I.R., R. Kwok and M.A. Fahnestock. 1998. Interferometric estimation of three-dimensional ice-flow using ascending and descending passes. IEEE Trans. Geosci. Remote Sens., 36(1), $25-37$.

Joughin, I., M. Fahnestock, D. MacAyeal, J.L. Bamber and P. Gogineni. 2001. Observation and analysis of ice flow in the largest Greenland ice stream. J. Geophys. Res., 106(D24), 34,021-34,034.

Joughin, I., S. Tulaczyk, R.A. Bindschadler and S. Price. 2002. Changes in West Antarctic ice stream velocities: observation and analysis. J. Geophys. Res., 107(B11), 2289. (10.1029/ 2001JB001029.)

Joughin, I.R., S. Tulaczyk and H.F. Engelhardt. 2003a. Basal melt beneath Whillans Ice Stream and Ice Streams A and C, West Antarctica. Ann. Glaciol., 36, 257-262.

Joughin, I., E. Rignot, C.E. Rosanova, B.K. Lucchitta and J. Bohlander. 2003b. Timing of recent accelerations of Pine Island Glacier, Antarctica. Geophys. Res. Lett., 30(13), 1706. (10.1029/ 2003GL017609.)

Joughin, I., D.R. MacAyeal and S. Tulaczyk. 2004a. Basal shear stress of the Ross ice streams from control method inversion. J. Geophys. Res., 109(B9), B09405. (10.1029/2003JB002960.)

Joughin, I., S. Tulaczyk, D. MacAyeal and H. Engelhardt. 2004b. Melting and freezing beneath the Ross ice streams, Antarctica. J. Glaciol., 50(168), 96-108. 
Joughin, I., J.L. Bamber, T. Scambos, S. Tulaczyk, M. Fahnestock and D.R. MacAyeal. 2006. Integrating satellite observations with modelling: basal shear stress of the Filcher-Ronne ice streams, Antarctica. Philos. Trans. R. Soc. London, Ser. A, 364(1844), 1795-1814.

Kamb, B. 1991. Rheological nonlinearity and flow instability in the deforming bed mechanism of ice stream motion. J. Geophys. Res., 96(B10), 16,585-16,595.

Kamb, B. 2001. Basal zone of the West Antarctic ice streams and its role in lubrication of their rapid motion. In Alley, R.B. and R.A. Bindschadler, eds. The West Antarctic ice sheet: behavior and environment. Washington, DC, American Geophysical Union, 157-199. (Antarctic Research Series 77.)

Larour, E., E. Rignot, I. Joughin and D. Aubry. 2005. Rheology of the Ronne Ice Shelf, Antarctica, inferred from satellite radar interferometry data using an inverse control method. Geophys. Res. Lett., 32(5), L05503. (10.1029/2004GL021693.)

Lowe, A.L. and J.B. Anderson. 2003. Evidence for abundant subglacial meltwater beneath the paleo-ice sheet in Pine Island Bay, Antarctica. J. Glaciol., 49(164), 125-138.

MacAyeal, D.R. 1989. Large-scale ice flow over a viscous basal sediment: theory and application to Ice Stream B, Antarctica. J. Geophys. Res., 94(B4), 4071-4087.

MacAyeal, D.R. 1992. The basal stress distribution of Ice Stream E, Antarctica, inferred by control methods. J. Geophys. Res., 97(B1), 595-603.

MacAyeal, D.R. 1993. A tutorial on the use of control methods in ice-sheet modeling. J. Glaciol., 39(131), 91-98.

MacAyeal, D.R. 1997. EISMINT: lessons in ice sheet modeling. Chicago, IL, University of Chicago. Department of Geophysical Sciences.

MacAyeal, D.R., R.A. Bindschadler and T.A. Scambos. 1995. Basal friction of Ice Stream E, West Antarctica. J. Glaciol., 41(138), 247-262.

MacAyeal, D.R., V. Rommelaere, P. Huybrechts, C.L. Hulbe, J. Determann and C. Ritz. 1996. An ice-shelf model test based on the Ross Ice Shelf, Antarctica. Ann. Glaciol., 23 $46-51$.

Parizek, B.R., R.B. Alley and C.L. Hulbe. 2003. Subglacial thermal balance permits ongoing grounding-line retreat along the Siple Coast of West Antarctica. Ann. Glaciol., 36, 251-256.

Paterson, W.S.B. 1994. The physics of glaciers. Third edition. Oxford, etc., Elsevier.

Payne, A.J., A. Vieli, A. Shepherd, D.J. Wingham and E. Rignot. 2004. Recent dramatic thinning of largest West Antarctic ice stream triggered by oceans. Geophys. Res. Lett., 31(23), L23401. (10.1029/2004GL021284.)

Price, S.F., H. Conway, E.D. Waddington and R.A. Bindschadler. 2008. Model investigations of inland migration of fast-flowing outlet glaciers and ice streams. J. Glaciol., 54(184), 49-60.

Rabus, B.T. and O. Lang. 2003. Interannual surface velocity variations of Pine Island Glacier, West Antarctica. Ann. Glaciol., 36, 205-214

Raymond, C.F. 2000. Energy balance of ice streams. J. Glaciol., 46(155), 665-674.

Rignot, E.J. 1998. Fast recession of a West Antarctic glacier. Science, 281(5376), 549-551.

Rignot, E. and S.S. Jacobs. 2002. Rapid bottom melting widespread near Antarctic ice sheet grounding lines. Science, 296(5575), 2020-2023.

Rignot, E., D.G. Vaughan, M. Schmeltz, T. Dupont and D. MacAyeal. 2002. Acceleration of Pine Island and Thwaites Glaciers, West Antarctica. Ann. Glaciol., 34, 189-194.
Rignot, E. and 6 others. 2008. Recent Antarctic ice mass loss from radar interferometry and regional climate modelling. Nature Geosci., 1(2), 106-110.

Rose, K.E. 1979. Characteristics of ice flow in Marie Byrd Land, Antarctica. J. Glaciol., 24(90), 63-75.

Scambos, T.A., T.M. Haran, M.A. Fahnestock, T.H. Painter and J. Bohlander. 2007. MODIS-based Mosaic of Antarctica (MOA) datasets: continent-wide surface morphology and snow grain size. Remote Sens. Environ., 111(2-3), 242-257.

Schmeltz, M., E. Rignot, T.K. Dupont and D.R. MacAyeal. 2002. Sensitivity of Pine Island Glacier, West Antarctica, to changes in ice-shelf and basal conditions: a model study. J. Glaciol., 48(163), 552-558.

Schoof, C. 2005. The effect of cavitation on glacier sliding. Proc. $R$. Soc. London, Ser. A, 461(2055), 609-627.

Shapiro, N.M. and M.H. Ritzwoller. 2004. Inferring surface heat flux distribution guided by a global seismic model: particular application to Antarctica. Earth Planet. Sci. Lett., 233(1-2), 213-224.

Shepherd, A., D.J. Wingham, J.A.D. Mansley and H.F.J. Corr. 2001. Inland thinning of Pine Island Glacier, West Antarctica. Science, 291(5505), 862-864.

Shepherd, A., D. Wingham and J.A. Mansley. 2002. Inland thinning of the Amundsen Sea sector, West Antarctica. Geophys. Res. Lett., 29(10), 1364. (10.1029/2001GL014183.)

Solomon, S. and 7 others, eds. 2007. Climate change 2007: the physical science basis. Contribution of Working Group I to the Fourth Assessment Report of the Intergovernmental Panel on Climate Change. Cambridge, etc., Cambridge University Press.

Thomas, R. and 17 others. 2004a. Accelerated sea-level rise from West Antarctica. Science, 306(5694), 255-258.

Thomas, R.H., E.J. Rignot, K. Kanagaratnam, W.B. Krabill and G. Casassa. 2004b. Force-perturbation analysis of Pine Island Glacier, Antarctica, suggests cause for recent acceleration. Ann. Glaciol., 39, 133-138.

Tulaczyk, S.M., B. Kamb and H.F. Engelhardt. 2000a. Basal mechanics of Ice Stream B, West Antarctica. I. Till mechanics. J. Geophys. Res., 105(B1), 463-481.

Tulaczyk, S.M., B. Kamb and H.F. Engelhardt. 2000b. Basal mechanics of Ice Stream B, West Antarctica. II. Undrainedplastic-bed model. J. Geophys. Res., 105(B1), 483-494.

Van den Broeke, M., W.J. van de Berg and E. van Meijgaard. 2006. Snowfall in coastal West Antarctica much greater than previously assumed. Geophys. Res. Lett., 33(2), L02505. (10.1029/2005GL025239.)

Vaughan, D.G., J.L. Bamber, M.B. Giovinetto, J. Russell and A.P.R. Cooper. 1999. Reassessment of net surface mass balance in Antarctica. J. Climate, 12(4), 933-946.

Vaughan, D.G., A.M. Smith, P.C. Nath and E. Le Meur. 2003. Acoustic impedance and basal shear stress beneath four Antarctic ice streams. Ann. Glaciol., 36, 225-232.

Vaughan, D.G. and 9 others. 2006. New boundary conditions for the West Antarctic ice sheet: subglacial topography beneath Pine Island Glacier. Geophys. Res. Lett., 33(9), L09501. (10.1029/2005GL025588.)

Vieli, A. and A.J. Payne. 2003. Application of control methods for modelling the flow of Pine Island Glacier, Antarctica. Ann. Glaciol., 36, 197-204.

Vieli, A., A.J. Payne, Z. Du and A. Shepherd. 2006. Numerical modelling and data assimilation of the Larsen B ice shelf, Antarctic Peninsula. Philos. Trans. R. Soc. London, Ser. A, 364(1844), 1815-1839.

Zotikov, I.A. 1986. The thermophysics of glaciers. Dordrecht, etc., D. Reidel Publishing Co. 